\title{
A Quantification Procedure for Interior Performance of Architectural Openings Associated with Dye-Sensitized Solar Cells
}

\author{
Jae-Hyang Kim ${ }^{1}$ and Seung-Hoon Han ${ }^{2, *(1)}$ \\ 1 Graduate School, Chonnam National University, Gwangju 61186, Korea; 101117@jnu.ac.kr \\ 2 School of Architecture, Chonnam National University, Gwangju 61186, Korea \\ * Correspondence: hshoon@jnu.ac.kr; Tel.: +82-62-530-1646
}

Received: 31 October 2019; Accepted: 13 November 2019; Published: 16 November 2019

\begin{abstract}
Windows with various colors are important design elements used widely ranging from traditional architecture to contemporary buildings to express the architectural façade, the interior atmosphere, and so on. Recently, there is a possibility that solar cells can be used to replace windows with various colors. In particular, attempts to manufacture windows using Dye-Sensitized Solar Cells (DSSCs) are actively underway. Accordingly, there is a need to determine physical and environmental performances of DSSCs. This study attempted a methodological approach to evaluate indoor environmental performance of windows and DSSCs. The concept of color gamut overage normally used in the field of displays was utilized to evaluate color expressions. In addition, a standard visual inspection table suggested by the International Ophthalmological Society was used to evaluate the recognition of shapes. This study compared performances between RGB color windows and DSSCs using the two above previous concepts. Measurement data showed that most DSSCs performed poorly in comparison with architectural color windows. However, some DSSCs showed good enough performances that could be used as alternatives of architectural color windows. Green DSSCs with VLT $18 \%$ had a color gamut similar to clear glasses. Blue DSSCs with VLT 18\% were found to have similar or better shape recognition than current architectural color windows. Based on these results, limitations of DSSCs as alternatives of architectural color windows and their future development directions are suggested.
\end{abstract}

Keywords: dye-sensitized solar cells; architectural window; indoor environment; color environment; shape recognition; color gamut overage

\section{Introduction}

Recently, the use of windows with various colors has been a design element in architectural procedure that has been defined steadily since the Gothic style. It is also used as an architectural element in contemporary architecture to express various façades and create an interior atmosphere. As glasses in green and blue colors rather than colorless glasses are used, colored windows have been applied to make an indoor environment comfortable in addition to its design characteristics. Recent studies have been conducted to apply semi-transparent solar cells for windows through developing Dye-Sensitized Solar Cells (DSSCs) and many types of organic units. For this kind of solar cells, the element of color is essential. Although colored glasses are used in various ways, there are few performance indicators regarding the indoor environment caused by these components. In particular, the performance of the perception for color and shape accepted through the window in a room is somewhat unreasonable for designers to judge as shown in Figure 1. To compare these performance factors, this study employed the concept of color gamut used in the area of display productions. The 
standard visual examination table used in ophthalmology was also used as a recognition method to evaluate shape. The aim of this study was to quantify the indoor environment by windows and comparing performances between windows and DSSCs.

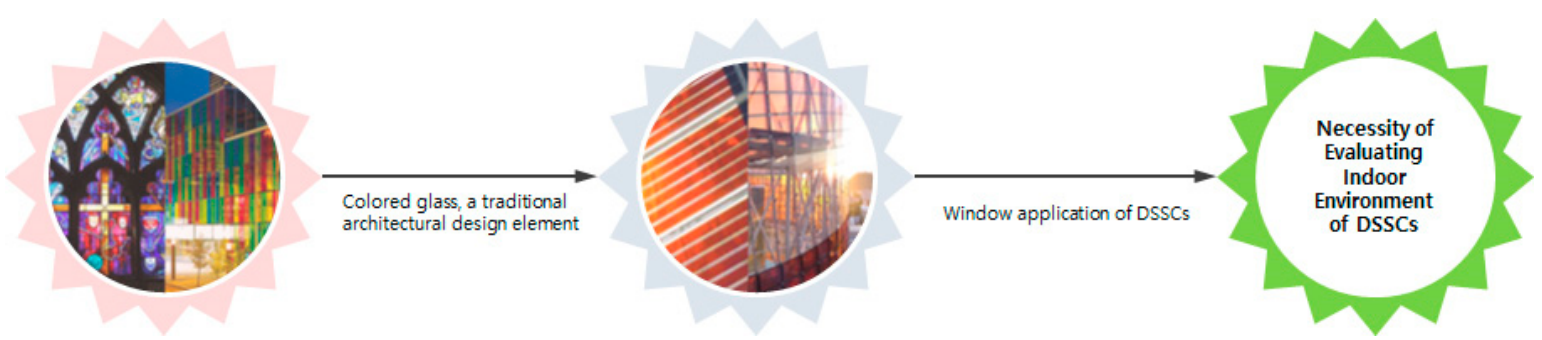

Figure 1. Necessity for evaluating performances of DSSCs.

Several studies have recently evaluated indoor conditions using windows and solar cells. However, studies focusing on the theme of interior performance of windows are insufficient. Most cases have focused on the illumination of the sun, the use of variable glass, light shelves and light tubes for providing proper lighting environments, and interior views by windows.

In a research performed by Hwang \& Lee, the manifestation of prospect-refuge concept was used to evaluate the view of occupants according to the type of windows. A comparative analysis could be performed using a simulation tool by deriving quantitative figures on the visibility according to window positions, sizes, and types [1]. Through that study, the perspective of design to select an appropriate window according to indoor use was made. In another study, a scale model was utilized to evaluate illumination performance of each type of transmission windows [2]. According to glass types such as general, colored, Low-e (energy), and pastel, illumination was measured by distance and analyzed after classifying these glass types into main forms such as general, double split, and half lit. Based on that study, considerations were made on how to create a lighting environment suitable for the indoor work. One study has investigated visual comfort and task performance by evaluating illumination systems using light shelves [3]. To evaluate the illumination performance of the light shelf, light distribution and luminance of the working surface were analyzed and questionnaires were used through evaluators based on mock experiments. Simulations have also been used to create graphical descriptions of the illuminance performance for light tubes and dish collectors [4]. In previous studies, indoor environmental evaluations were mostly related to illumination and vista with scaled mock-up model, simulations, and questionnaires as main study methods.

In addition to the evaluation of illuminance and view, some studies have also assessed the indoor environment of colored glass. In a study of Chung, the lighting atmosphere of the atrium as a transparent interior space according to glass color was evaluated using scaled model and survey method [5]. However, the main content of the questionnaire was composed of emotional contents such as bright, dark, glare, warm, and cold, making it impossible to define their numerical values. Although windows are not chosen as study targets, attempts have been made to evaluate the indoor environment in color. Comparatively, Kim has developed a program called Color Quality Assessment Tool (CQAT) to overcome limitations of simulation of colored indoor environment according to lighting and finishing [6]. In another study, validation of the CQAT program has been attempted with some data such as lumen, color coordinates, Color Correlated Temperature (CCT), and so on to measure the accurate color environment [7]. Spectral Power Distribution (SPD) and Circadian Action Factor (CAF) have also been employed as traditional methods for color quantification. However, these methods need an expensive spectrometer and require specialized knowledge for analyses, although they provide relatively accurate data that could be reflected in simulations.

Solar cells can be classified into three generations by each type of representative solar cells including crystalline (Si), thin film structure, and compound solar cell like DSSCs used in satellites as next generation solar cells [8]. As generation goes up, the efficiency of power generation decreases. 
Its potential to be used as design elements such as various colors and increased transparencies is summarized in Table 1.

Table 1. Classification of solar cells by characteristics.

First Generation

Especially, DSSC is a type of solar cell in which polymer dye is responsible for light absorption of incident light and $\mathrm{TiO}_{2}$ Oxide semiconductor is responsible for charging transfers. Various colors can be produced depending on the arrangement of dyes. The transparency can be adjusted freely in this concept. For this reason, DSSCs have the advantage in easy application to windows and in mass production as their raw materials are relatively cheap. On the other hand, they have the disadvantage of low production power, although can be installed in a large area when they are applied to glass windows. Thus, they are considered to have sufficient values in terms of energy production. Recently, studies on their material parts are relatively active. However, studies on their proper color and transparency for application as architectural elements are insufficient, making it difficult to select appropriate standards.

In response to earlier demands, this study aims to compare the indoor environment of ordinary windows with DSSCs towards commercialization, revealing the possibility of window components with DSSCs and presenting their future development direction. It also aims to provide data on the interior environment that the architectural designer wants to produce. This study deals with items of indoor color environment and shape recognition. It uses quantitative measurement, mock-up test, and questionnaire as research methods. According to previous studies, quantitative measurement of color should be made by SPD and CAF. However, they require high cost and full expertise which can lead to problems when communicating with information during the commercialization and the design processes by architectural experts. To address this problem, a new quantitative measurement method with low cost and high understanding is needed.

Targets for this study are clear and colorful glass windows commonly used in architectural designs for the purpose of controlling an indoor environment. DSSC windows that are being actively studied 
as building openings are also targets of this study. In addition to setting a control group, window applicability was examined by measuring color gamut overage used in the field of display. The process of measuring and comparing shape recognition of each window based on the visibility distance by the Landolt ring shape, a standard mark used in visual treatment, was conducted as described in Figure 2 in detail.

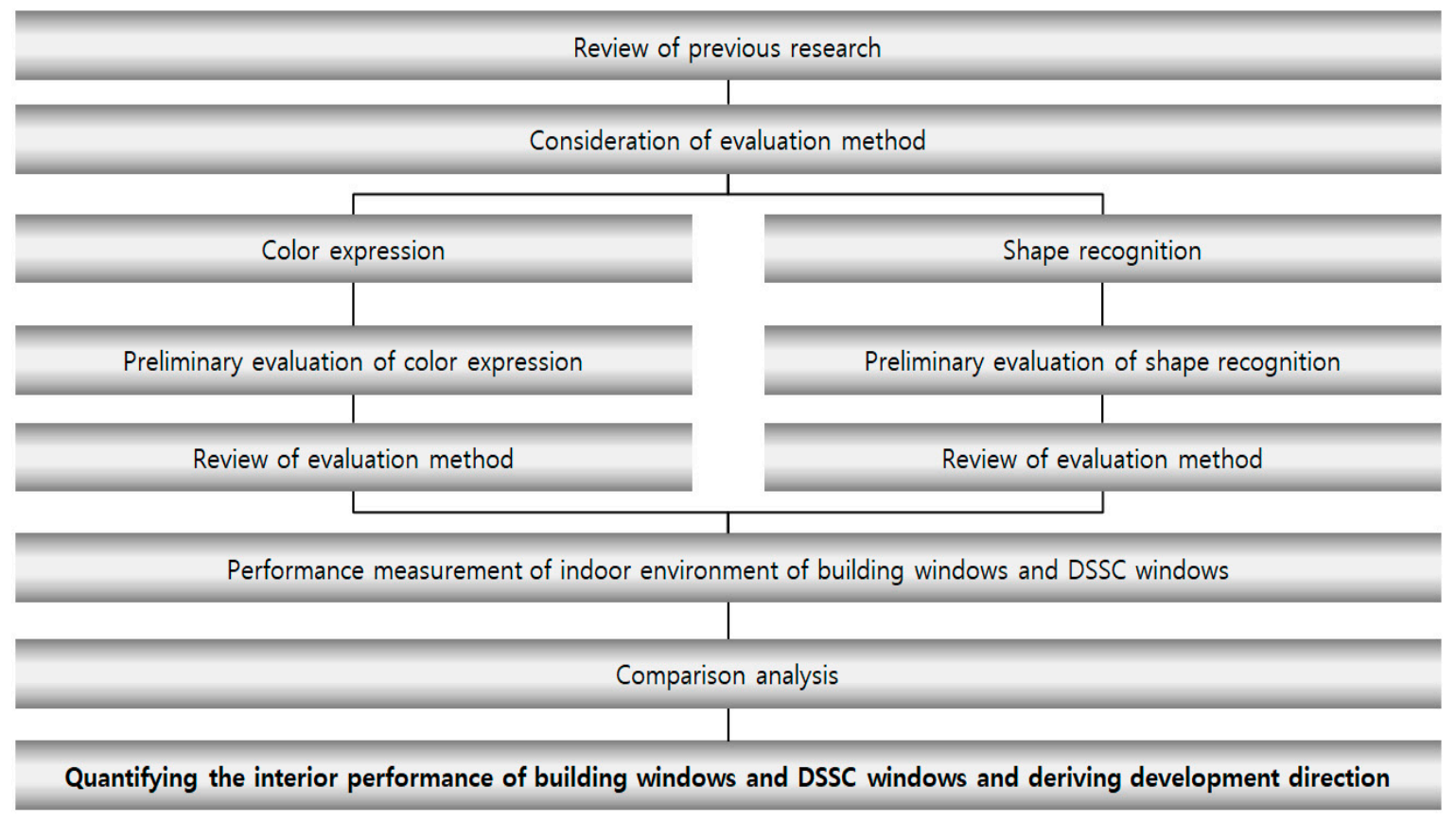

Figure 2. Framework of this study.

\section{Evaluation Methods}

Major factors affecting the interior of color windows and dye-sensitized solar cells have been previously studied in various environments such as light, temperature, color, and shape recognition [9]. In case of light environment, it can be measured as illuminance by evaluating the amount of sunlight entering the room. Thermal environment can be measured based on surface temperature by evaluating heat absorption according to color and the amount of electricity production. There is no appropriate evaluation method for shape recognition environment so far. Color environment can be quantitatively measured with a spectrometer. However, it is difficult to measure with string requirements of cost and expertise. For this reason, most current measurement methods for indoor environment are limited to lighting and thermal environments. Therefore, this study will discuss shape recognition of colored environments. This has not been exploited yet in previous studies.

\subsection{Color Expression}

Performance factors related to colored indoor environment were defined as color expression. It was based on color gamut overage factors utilized for assessing display performances. They were also defined as color expression because colored windows should be approached with the concept of representation rather than reproduction. Color reproducibility of the display can be determined by its colors with gamut overage. The larger the number of the display color exists, the more precise the color reproduction is. Color gamut overage is an indicator of how many color indexes can be reproduced in comparison with its standard range. Digital equipment is normally operated to evaluate the ratio of the color expression area in sRGB (Standard Default Color in Red, Green and Blue) system [10]. There are several ways to express color gamut, including the ratio against NTSC (National Television System Committee) color gamut, the rate through 3D color space in CIE (Commission Internationale d' Eclairage meaning International Commission on Illumination in English) LAB ( $\mathrm{L}^{*} \mathrm{a}^{*} \mathrm{~b}^{*}$ color space), 
and VCRC (Volume-Color Reproduction Capability) CIECAM02 (Color Appearance Model by CIE published in 2002), and so on. This color gamut is relatively simple to measure with a normal calibration equipment. In addition, visual representation of the color gamut implemented on display has an advantage in that it provides data that can be easily understood. Previous studies on color reproduction have been conducted with two main perspectives.

The most active research field is increase of color reproduction rate of display that includes various developments in color filter, backlight, and operation algorithm. In Liqiang's study, a cost-effective strategy based on a color-filtered Phosphor-in-Glass (PiG) has been proposed [11]. In his/her other works, $\mathrm{NdF}_{3}$ glass ceramics were developed with a special filter capable of expressing a wider color gamut [12]. Another advanced research was also conducted to reduce the thickness of color filters by developing color filters based on dyes [13]. Studies on backlight development using $\mathrm{CsPb}(\mathrm{Br}, \mathrm{I})_{3}$-embedded glasses to express a much wider color gamut have also been performed [14]. A display gamut using LED/Laser light sources has been suggested as well [15]. Furthermore, researches on the development of local dimming algorithms to improve the efficiency of 32-inch LED backlight and manipulate color gamut have been actively conducted [16,17]. David has explained a different perspective for environmental factors affecting color gamut and terms for the relationship between display gamut and ambient illumination [18]. In addition, analyses on color display gamut against luminance by varying the ambient lighting conditions have been carried out by Satoru [19]. An assessment method with the change of color gamut and tone curves according to ambient light conditions has been reported by $\mathrm{Xu}[20]$.

By using the suggested color gamut principle, a measurement method of color expression for openings has been proposed. It could be measured by attaching a device to obtain data for color gamut on the display surface. Since the display is made up of several layers, this study tries to employ a measurement technique for the gamut by adding a new layer as the color window. In this case, it is possible to compare the color reproducibility of the existing display with its reproducibility of the layer-added display. It is also possible to infer the performance of the color representation of the added layer. Therefore, it is possible to visually express what colors are expressed in the coordinate system by looking at the outside through the colored window as shown in Figure 3.

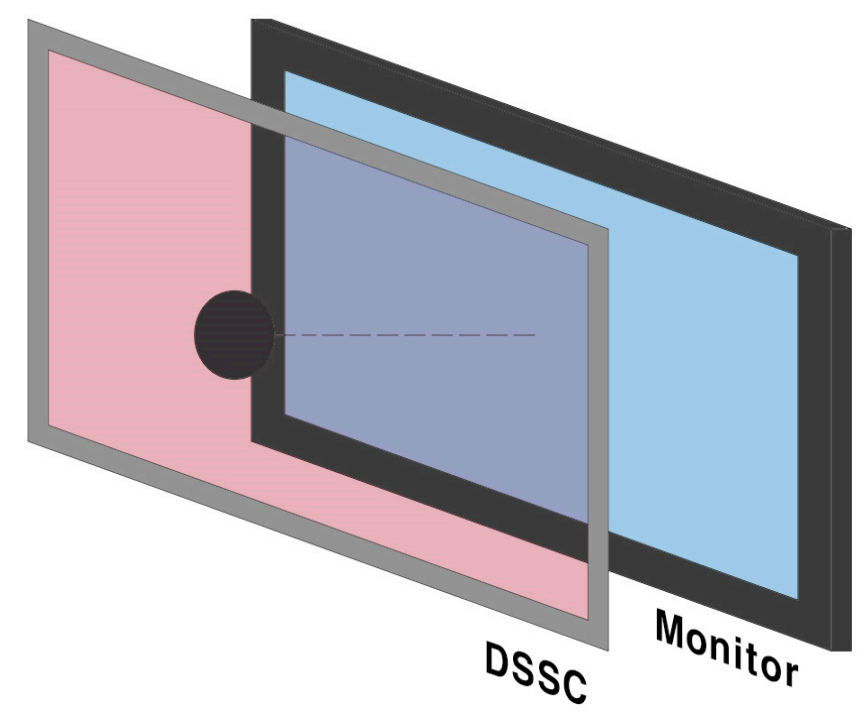

Figure 3. Proposed method for measuring color expression.

The following settings were made for color expression measurement: installing the equipment, fixing the target, setting environment, and operating the evaluation method. For this study, Datacolor's Spyder5 ELITE was used for measuring color gamut and Yamasaki's Catleap monitor was applied as the standard display. Measurement targets were three kinds of windows with attached RGB color film papers in three different colors: Red-based DSSCs at Visible Light Transmittance (VLT) of 7\%, 
$10 \%$, and $18 \%$, Green-based DSSCs at VLT of $7 \%$ and $18 \%$, and Blue DSSCs at VLT of $7 \%$ and $18 \%$. To minimize the interference of the air layer, the distance between the object and the standard monitor was measured as closely as possible. According to previous studies, external interference such as diffuse reflection and lighting could affect the data depending on the surrounding environment. Therefore, a dark room-type measurement environment was set up to create an environment free from external interference. As a result, representation of measured values in color expression for each measurement object has been expressed in a coordinate system. In the display, it is expressed as the ratio of area based on sRGB. However, since this study is about the color that can be expressed through openings and DSSCs, the area ratio does not have much meaning [10]. Therefore, it aims to provide data on the range of color expression, not area ratio. Based on this, a comparative analysis is conducted for each control group.

An analysis of problems that might occur when conducting tests in the proposed method was then conducted. First, an analysis of how interference might occur in color expression measurement is needed when applying the method devised before measuring it. Preliminary tests were conducted on effects of intercalated windows and DSSC layers and the amount of interference in mid-air layers. These tests were performed by comparing the color reproduction of the standard monitor with the color representation when colorless transparent glass at VLT of $89 \%$ was inserted as described in Table 2. As a result of the test, the area was almost unchanged when the colorless transparent glass was inserted in this state. Thus, the proposed measurement method could be used effectively.

Table 2. Preliminary test to check color expression interference.

\begin{tabular}{|c|c|c|c|}
\hline & Division & 1st Test & 2nd Test \\
\hline Display & - & & \\
\hline Clear Glass & $\begin{array}{c}\text { Visible light } \\
\text { transmittance (VLT) } 89 \%\end{array}$ & & \\
\hline
\end{tabular}

In addition, it was necessary to examine how color expression would change according to changes of VLT variables. VLT is important for DSSCs because the power generation efficiency varies with VLT. Therefore, it is required to examine the correlation between VLT and color expression. For verification, the test was carried out using a discoloration device in which the VLT changed according to the amount of electrons retained without any color change as summarized in Table 3. 
Table 3. Color expression according to VLT.

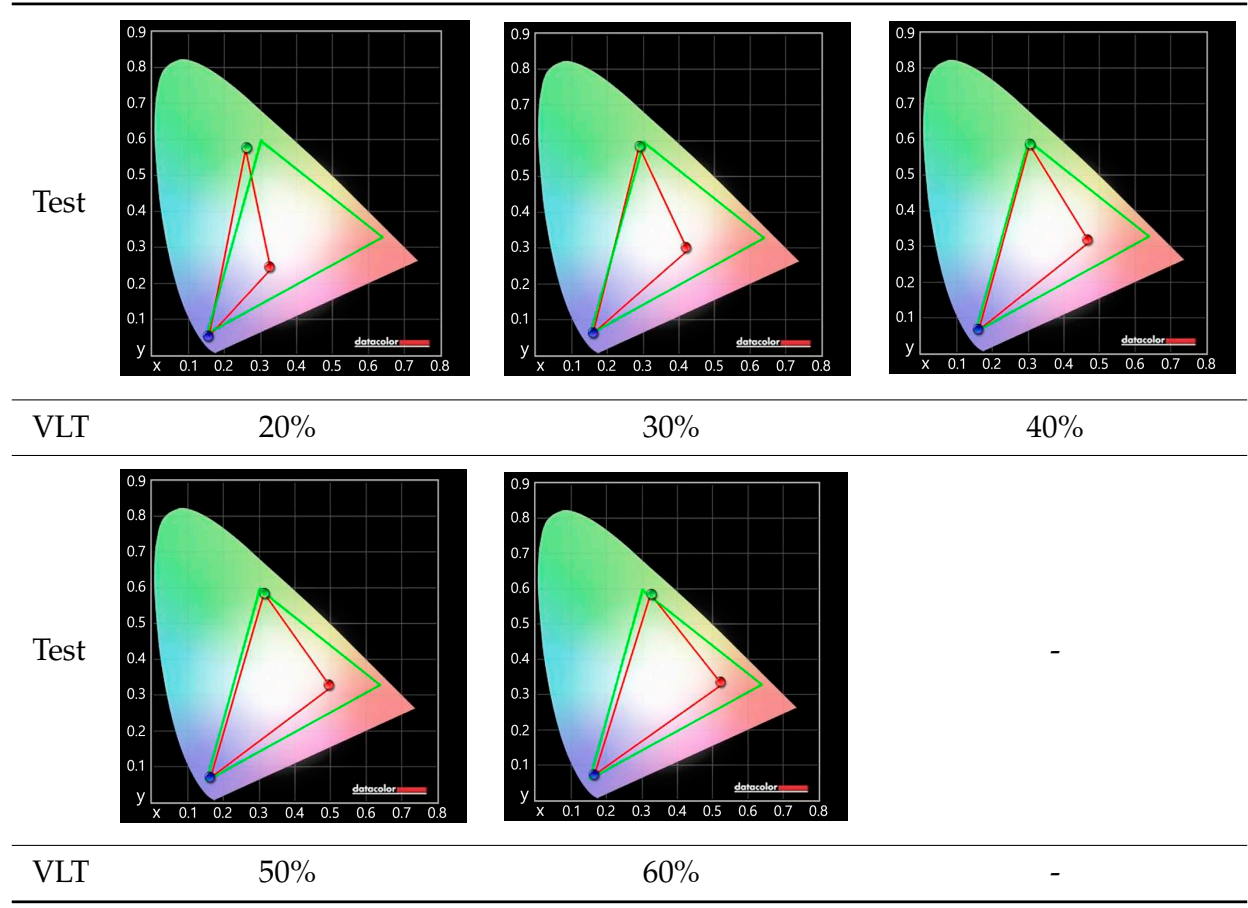

As a result of testing the VLT ranging from $20 \%$ to $60 \%$ in $10 \%$ scales, the area was enlarged with a certain direction as the VLT increased. In addition, the lower the VLT range was distributed, the more the range of color expression changed. The graph was extracted by comparing it with the triangular area of clear glass. The size of the area where the color could be expressed changed according to VLT when the color expression of transparent glass was 100\%. When the VLT was increased, the color expression was analyzed to obtain a logarithmic function relationship. At low VLT, the color expression was also very low. However, almost all colors could be expressed when VLT exceeded $40 \%$, although they depended on the amount of dye as shown in Figure 4.

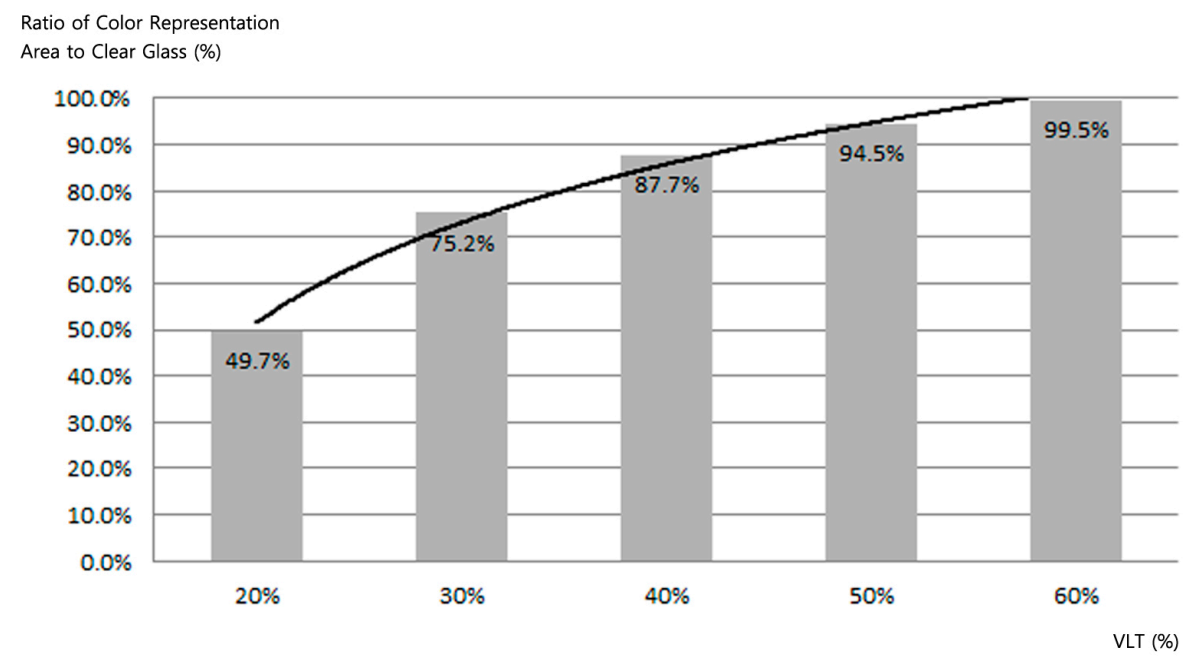

Figure 4. Color representation of clear glasses per VLT.

\subsection{Shape Recognition}

The interpretation of visual information and its action can be divided into three stages of 'sense-perception-cognition' [21]. In this test, the perception-cognitive ability of target objects is being studied for the visibility of openings. Therefore, the study was planned by analyzing perceptual 
and cognitive characteristics based on the Gestalt theory. Perceptual characteristics of visible periods include visual field and perceptual homeostasis. The visual field is the area where humans can see a clear image of an object. Perceptual homeostasis refers to consistent perception of information such as size, shape, and brightness from an object even if data transmitted from a specific object will change. When an object has a lot of stimulus about a familiar object or visual information from it, the brain corrects information on the object status regardless of the heterogeneous information conveyed. Human perception can be divided into three stages: sense, perception, and cognition. Relationships among these stages have studied previously [21]. In addition, types of perception in terms of form, color, texture, contour, and movement have been determined in a previous research [22]. Based on the above theory, the perception of an object can be classified into four perceptions: size perception, color perception, depth perception, and movement perception [23]. Movement perception can be recognized as compound perception. Size recognition and depth recognition can be handled the same. In case of color perception, an evaluation was carried out using the method implemented earlier. Therefore, this research was conducted based on size recognition.

The suggested test was performed to recognize the Landolt ring shape with a gap in one direction in the ring. It was adopted by the International Academy of Ophthalmology (IAO) in 1909 as a unit time based on minimum separable acuity [24]. Shape evaluation with Landolt ring has also been used in other fields. For example, J. McAnamy have used it to define spatial frequencies that underlie judgments of Landolt C [25]. In addition, previous studies have investigated the development of children's vision through Landolt rings [26] and the effect of color on its recognition [27]. In cases of colored windows and DSSC, the minimum separation power may be reduced for external visual environment. Thus, the evaluation can be conducted by introducing the Landolt ring target.

The following settings were made for the shape recognition test: installing the equipment, fixing the target, setting the environment, and operating the evaluation method. For the evaluation, Landolt rings are written in three dimensions such as $\mathrm{C} 1$ at $37.5 \mathrm{~mm}$ by $37.5 \mathrm{~mm}, \mathrm{C} 2$ at $17.5 \mathrm{~mm}$ by $17.5 \mathrm{~mm}$, and C3 at $7.5 \mathrm{~mm}$ by $7.5 \mathrm{~mm}$. After each sample was installed on openings of the mock-up, photographs have been stored with a DSLR (Digital Single-Lens Reflex) camera from $3 \mathrm{~m}$ to $18 \mathrm{~m}$ per target sheet as explained in Figure 5.

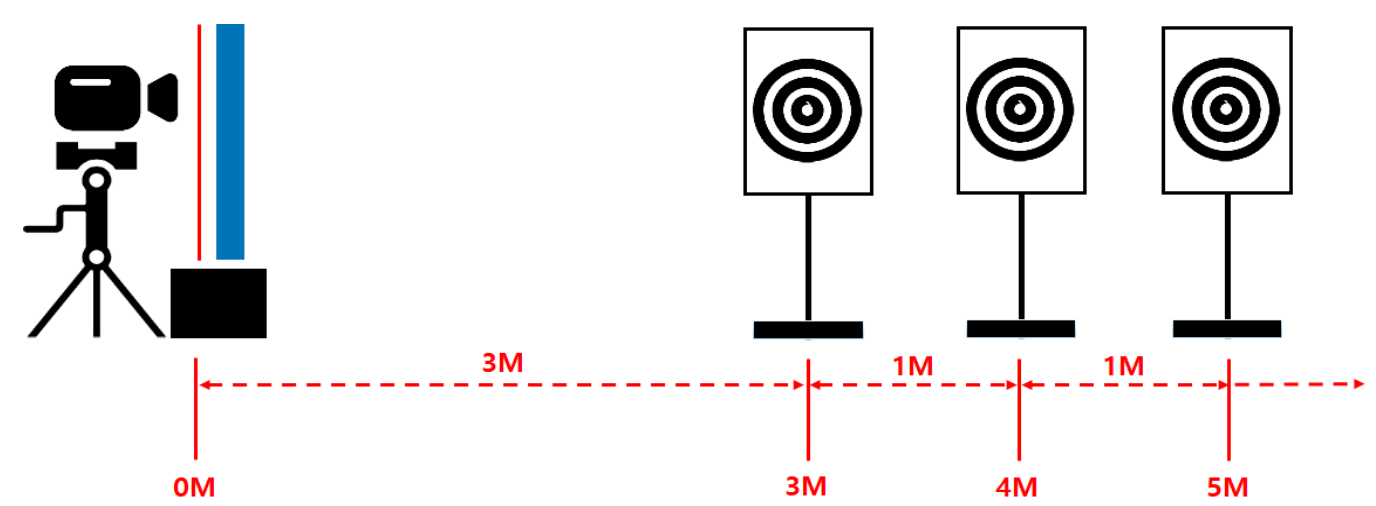

Figure 5. Sample installation and photographing on the mock-up.

Measurement targets are the same three kinds as the previous test with attached RGB color film papers to openings in three different colors: Red-based DSSCs at Visible Light Transmittance (VLT) of $7 \%, 10 \%$, and $18 \%$, Green-based DSSCs at VLT of $7 \%$ and $18 \%$, and Blue DSSCs at VLT of $7 \%$ and $18 \%$. Obtained pictures were sent to TV screens and provided to reviewers. At this time, the indoor environment was created based on 200 Lux that should be provided for visual inspection. Evaluators conducted a test by viewing and orienting photographs of Landolt rings taken at consecutive distances. After that, test papers were collected and incorrect answers were checked. Based on the distance at which the first incorrect answer occurred, a score for the shape recognition distance was given and the trend was confirmed by graphing scores obtained. 
A preliminary evaluation was conducted with six preliminary evaluators to examine whether color or VLT affected shape recognition. For evaluation, shape recognition distances of preliminary evaluators for DSSCs in red, green, and blue with the same VLT at 7\% were calculated. Results are shown in Table 4.

Table 4. Shape recognition graph per color.

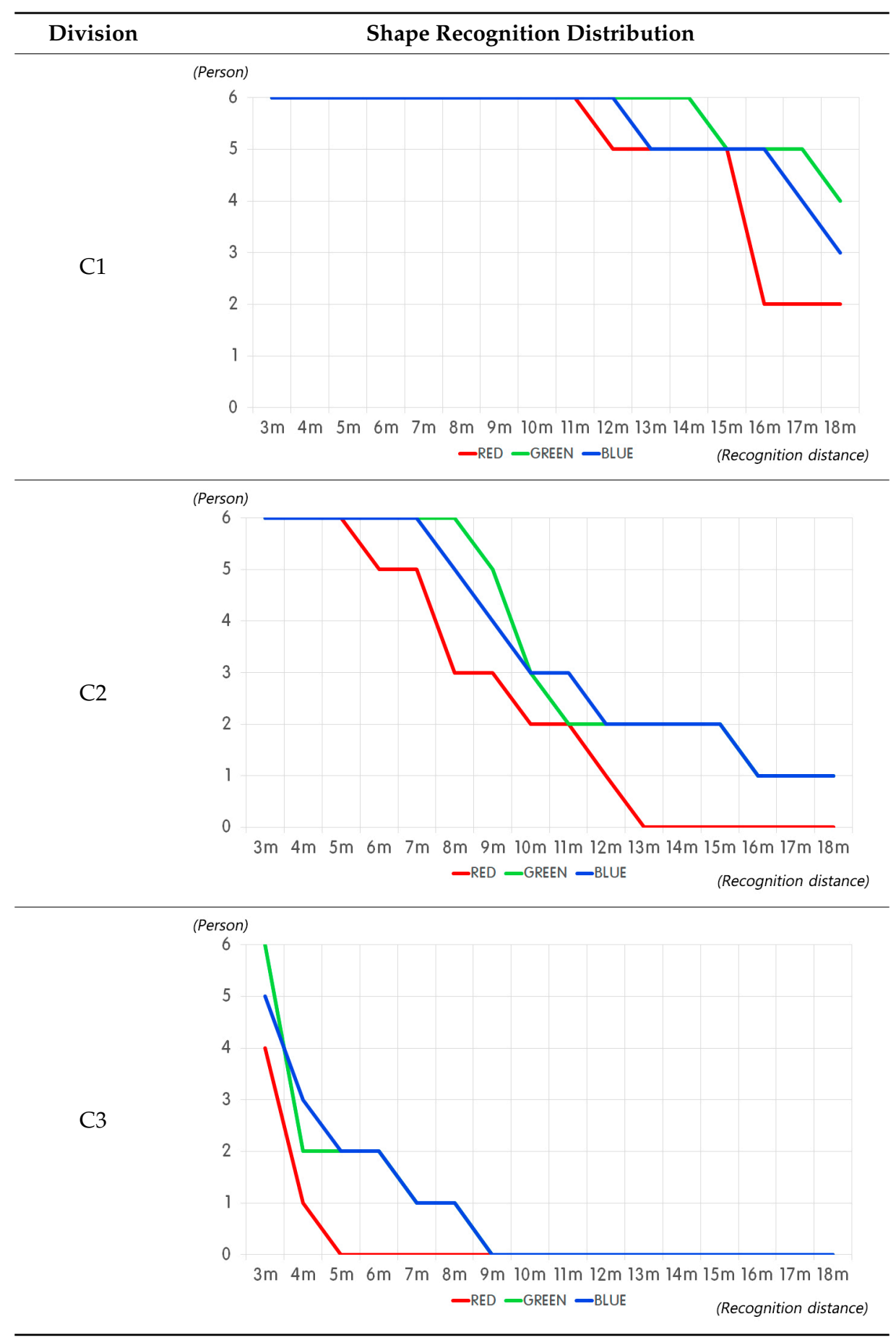

It was found that the distance for recognizing the Landolt ring was different according to the color. The average shape or distance of each product was calculated by averaging data for each sample. In the case of $\mathrm{C} 1$, the Landolt ring shape was not recognized at $15.33 \mathrm{~m}$ in red, $17.17 \mathrm{~m}$ in green, or 16.50 $\mathrm{m}$ in Blue. In the case of $\mathrm{C} 2$, the shape was not recognizable at $8.50 \mathrm{~m}$ in red, $11.50 \mathrm{~m}$ in green, or 11.33 
$\mathrm{m}$ in blue. In the case of $\mathrm{C} 3$, the Landolt ring was not recognizable at $3.25 \mathrm{~m}$ in red, $4.33 \mathrm{~m}$ in green, and $4.80 \mathrm{~m}$ in blue one as shown in Figure 6.

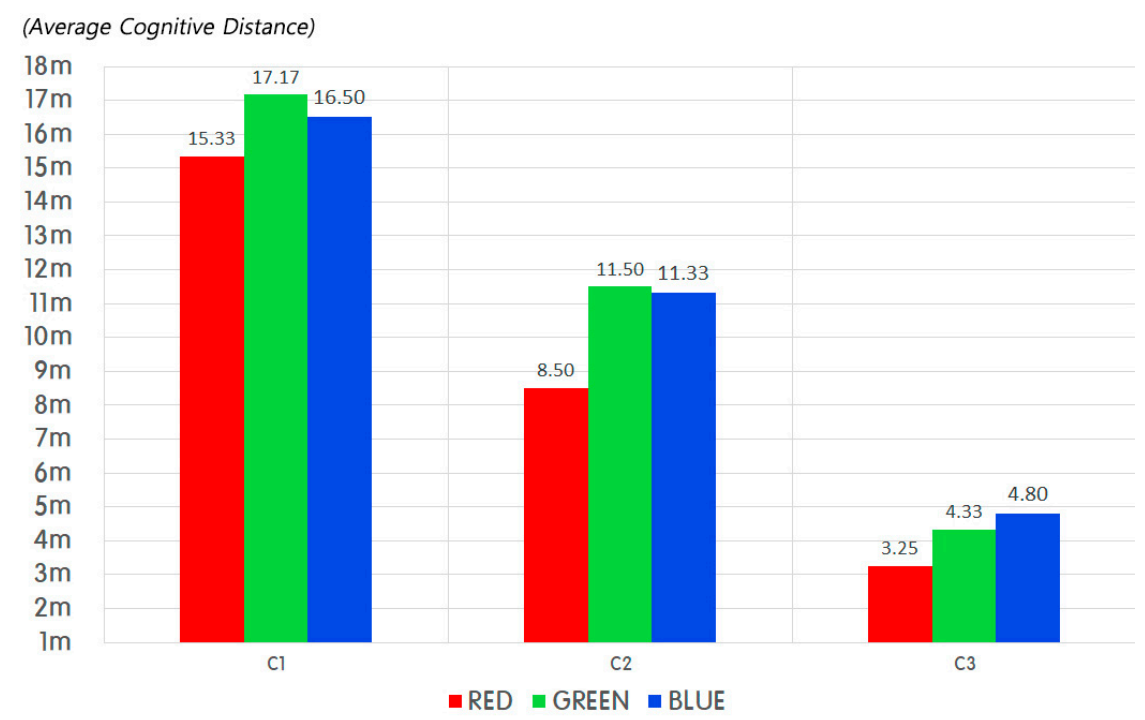

Figure 6. Preliminary results of feature recognition of DSSCs at VLT of 7\%.

For evaluation, distances were calculated for DSSCs in Red at VLT of 7\%, 10\% and $18 \%$ that were situated for the same color with different VLTs were obtained by six preliminary evaluators. Results are shown in Table 5.

Table 5. Shape recognition graph per VLT.

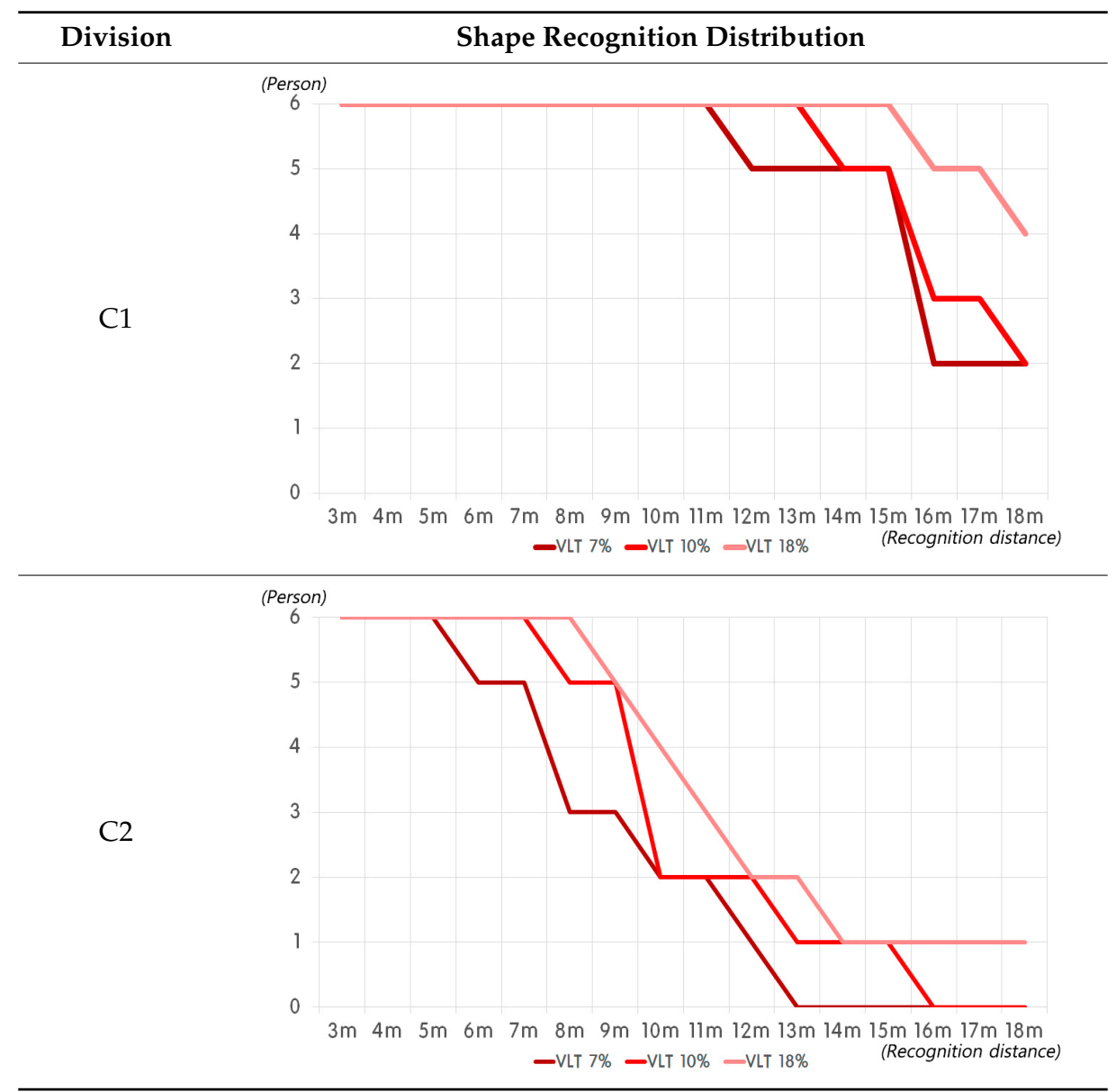


Table 5. Cont.

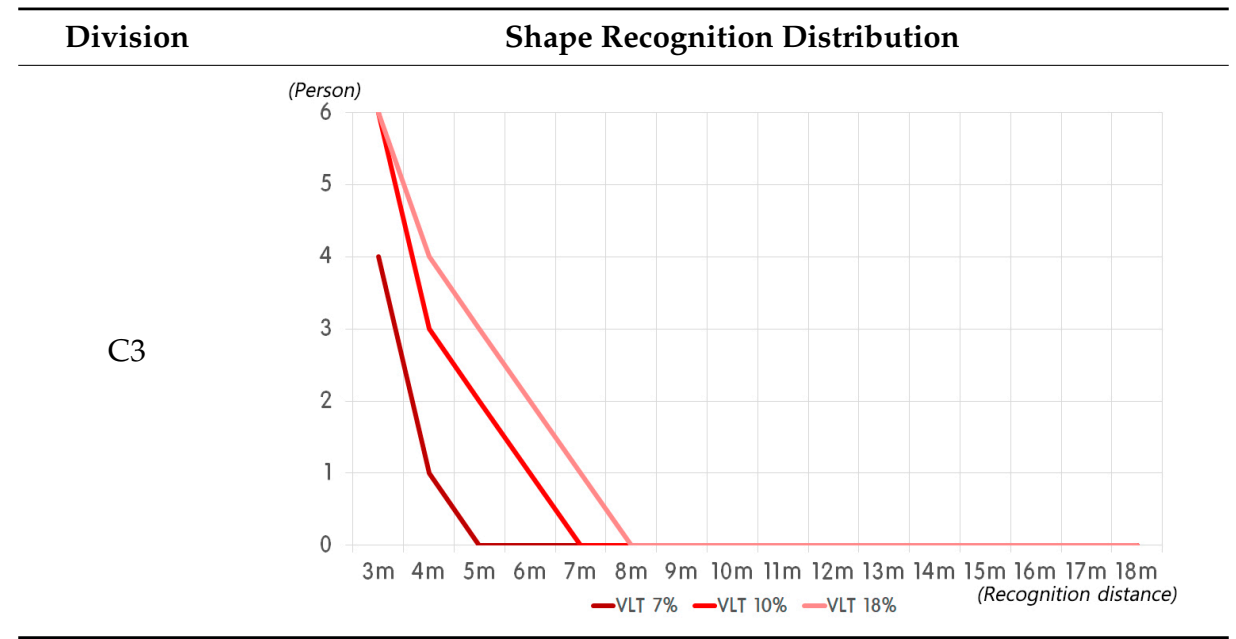

According to VLT values, it was confirmed that the distance for recognizing the Landolt ring was different. The average shape or distance of each product was calculated by averaging data for each sample. In the case of $\mathrm{C} 1$, the Landolt ring shape was not recognized at an average of $15.33 \mathrm{~m}$ for VLT at $7 \%, 16.00 \mathrm{~m}$ for VLT at $10 \%$, or $17.33 \mathrm{~m}$ for VLT at $18 \%$. For C2, the shape was not recognizable at $8.50 \mathrm{~m}$ for VLT $7 \%, 10.17 \mathrm{~m}$ for VLT $10 \%$, or $11.50 \mathrm{~m}$ for VLT $18 \%$. In the case of C3, the Landolt ring was not recognizable at $3.25 \mathrm{~m}$ for VLT 7\%, $4.33 \mathrm{~m}$ for VLT $10 \%$, or $4.67 \mathrm{~m}$ for VLT $18 \%$ as shown in Figure 7.

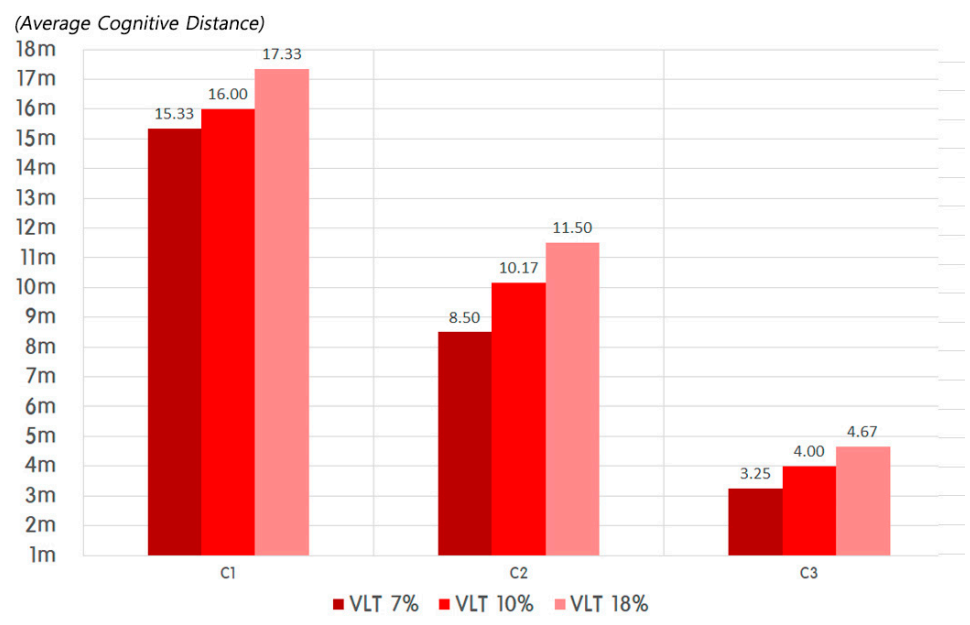

Figure 7. Preliminary evaluation results in shape recognition of red DSSCs per VLT.

Through interference measurement of color expression for the inserted object, it was confirmed that there was no big problem for the selected evaluation method. In addition, preliminary tests confirmed that both color and VLT directly influenced color expression and shape. Therefore, it was judged that the evaluation of the indoor environment controlled by openings and DSSCs with colors could be applicable through the method of the test mentioned above.

\section{Results}

\subsection{Evaluation of Color Expression}

Based on the proposed method, color expression measurements were performed for three RGB-based glass films and seven windows with RGB-based DSSCs twice for comparison and review. Results were investigated based on generated data to represent the same or similar values for color and 
VLT as follows. Red-based DSSCs were able to confirm that green-based expressiveness increased with higher VLTs as described in Tables 6 and 7. In comparison with VLT 18\%, VLT 7\% had an area ratio of $35.2 \%$ and VLT $10 \%$ had an area ratio of 39.2\% as shown in Table 6 in detail. In cases of windows with red films, colored window in blue was better than red DSSCs while the green color was much inferior as shown in Tables 6-8. In cases of green-based DSSCs, it was confirmed that the region formation was very different depending on the VLT value. This could be partly due to the type of dye and electrolyte used for VLT. In case of the green film at VLT 27, green-based DSSCs could be seen with a larger range for the color expression as shown in Table 7. On the other hand, blue DSSCs showed a slight increase in red-dot expressions with increasing VLT, although they had little expression in comparison with red DSSCs. Therefore, only green and blue could be expressed. VLT 7\% had an area ratio of $15.8 \%$ compared to VLT 18\%. In cases of openings with blue films, the red dot was more expressive than blue DSSCs. However, the red color is almost impossible to represent as explained in Table 8.

Table 6. Measurements of color expressions for red-type windows and DSSCs.

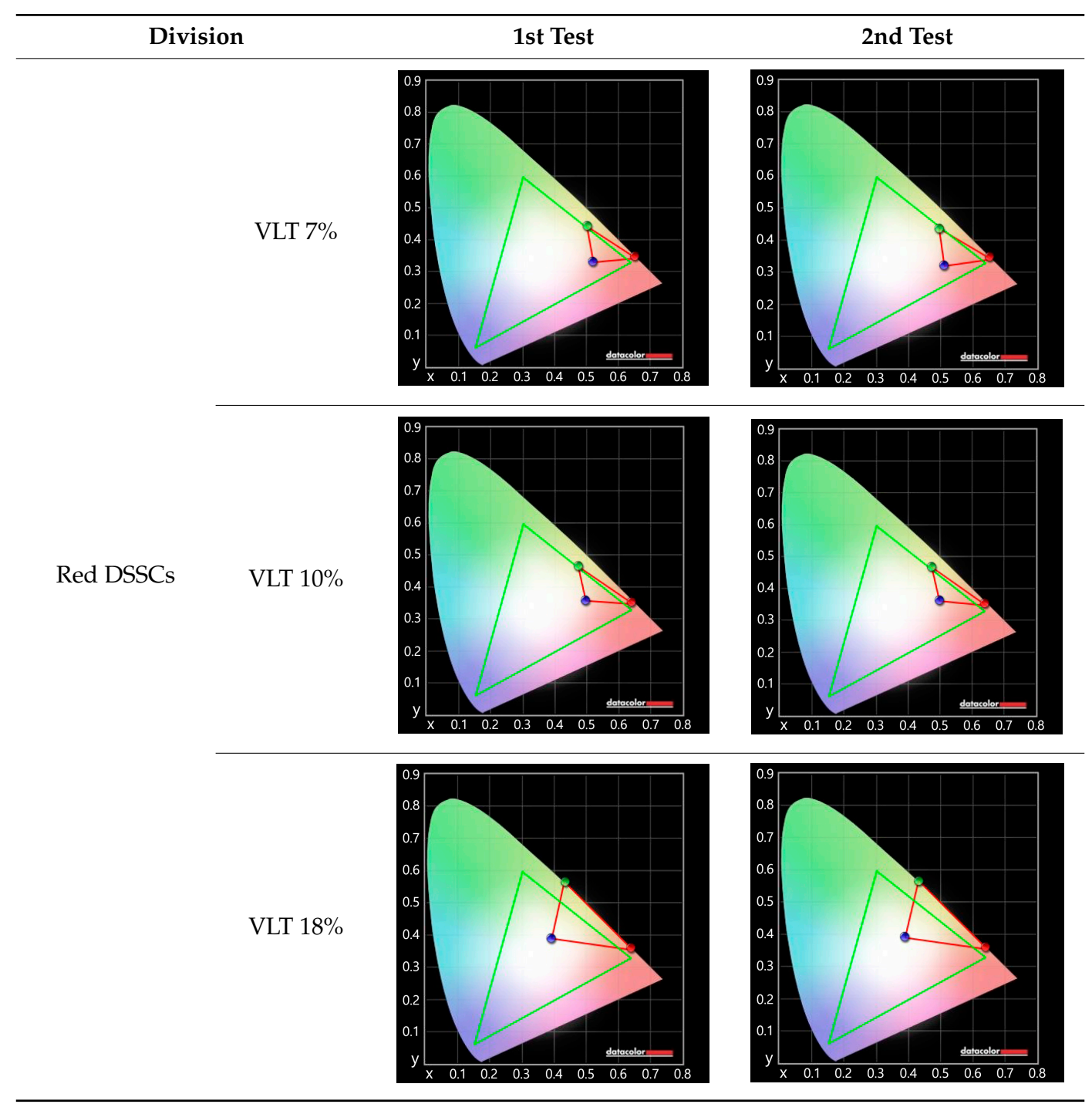


Table 6. Cont

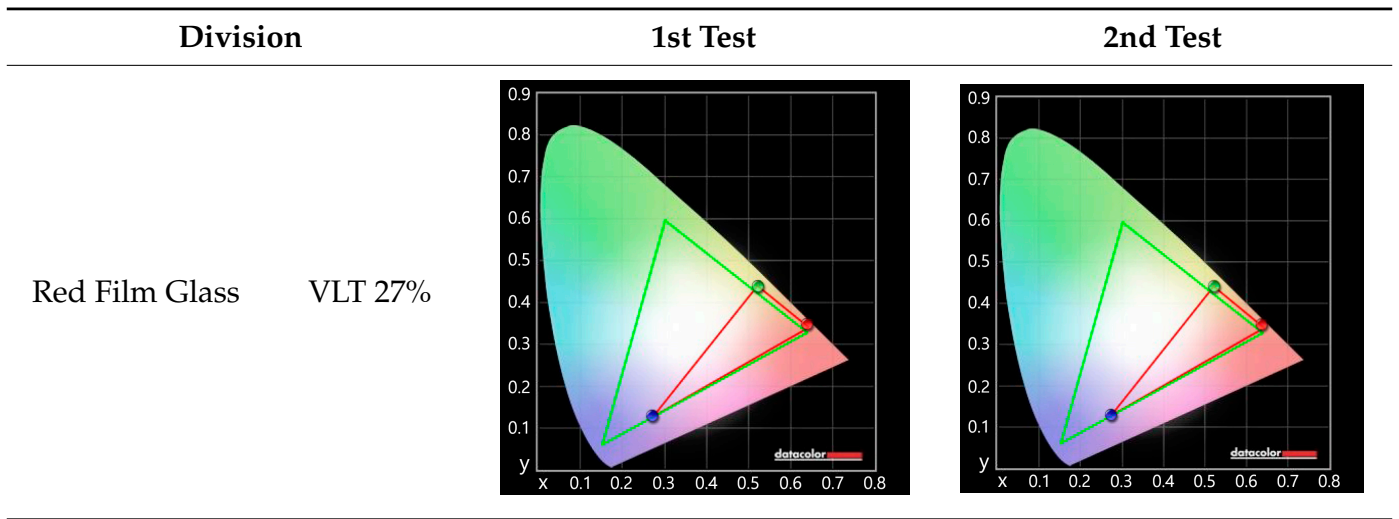

Table 7. Measurements of color expressions for green-type windows and DSSCs.

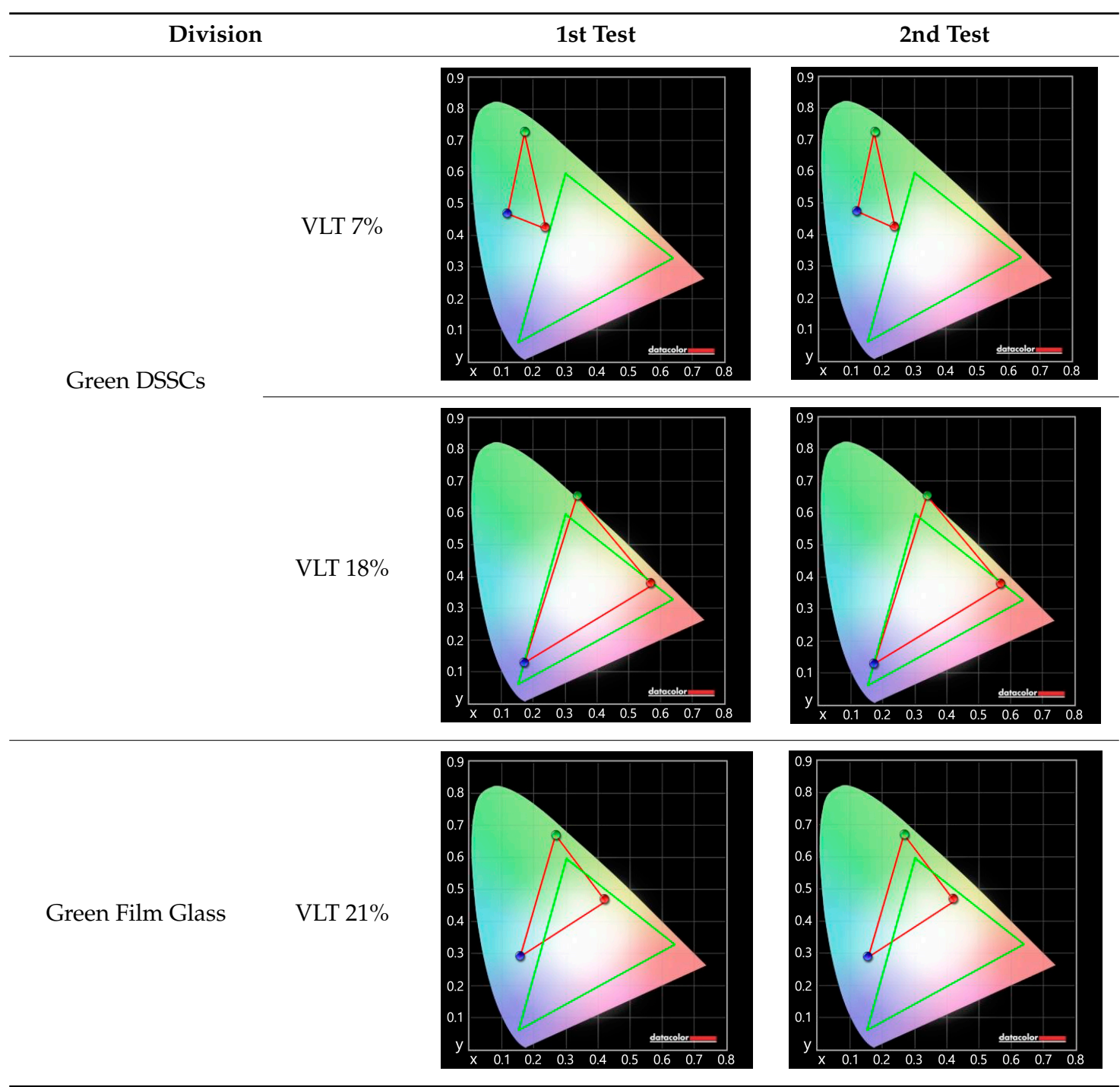


Table 8. Measurements of color expressions for blue-type windows and DSSCs.

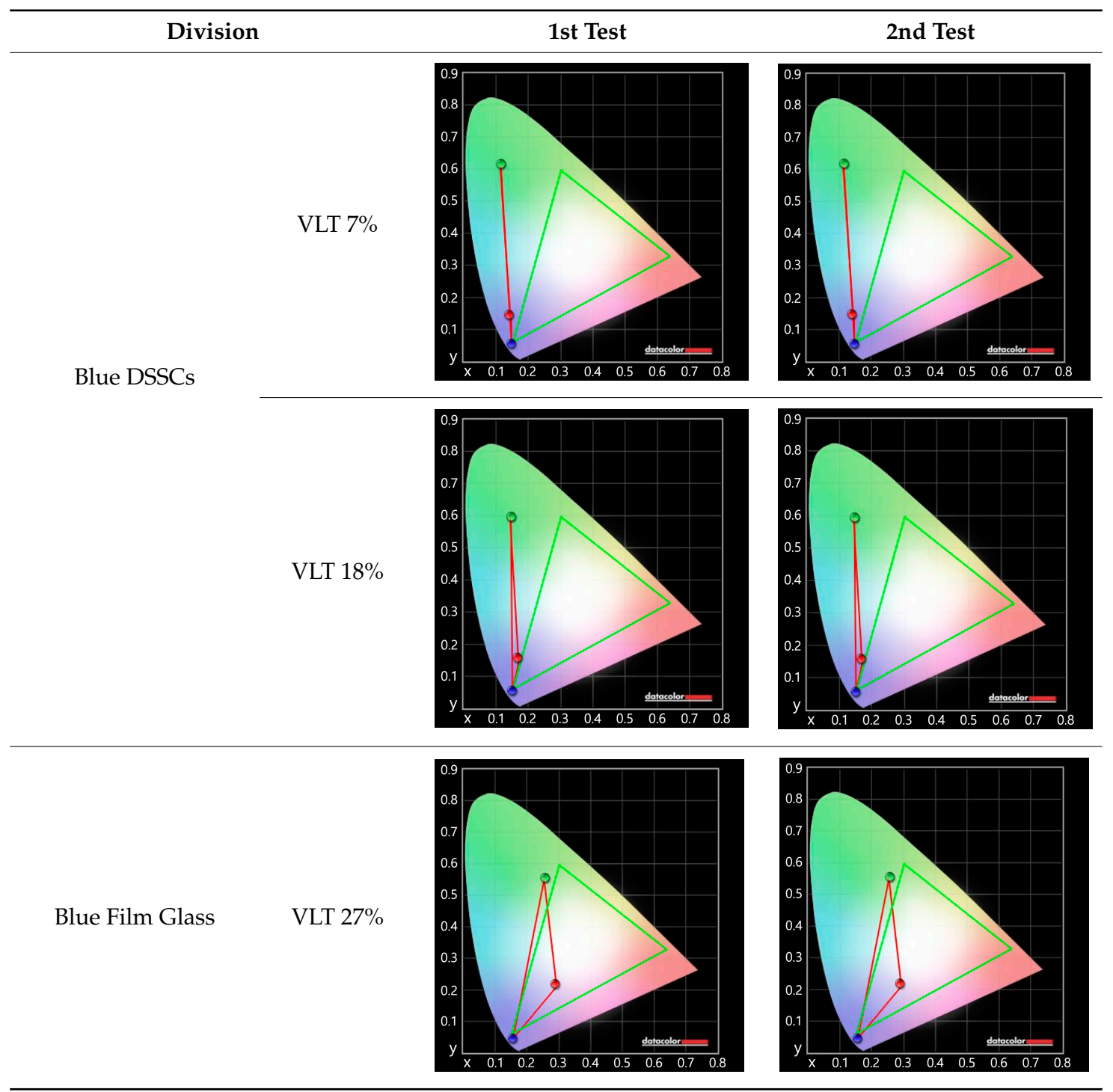

\subsection{Evaluation of Shape Recognition}

Based on the proposed shape recognition method, fifteen evaluators who retained more than 0.8 left and right correction criteria in visibility and trained in environmental performance of DSSCs and building windows in advance were recruited. The test period consisted of fourteen days with corrected roughness to 200 lux in illuminance. Reviewers were divided into one to three people during the evaluation for more trustful tests.

Compared to transparent glass, it was confirmed that openings with DSSCs and windows to which the color film was attached shortened the visible distance between Landolt rings. The larger the sample size, the smaller the difference in recognition distance compared to the transparent glass. In addition, the smaller the sample size, the larger the recognition distance difference. In addition, regardless of color, the lower the VLT, the greater the difference in perceived distance after all. Based on the average shape recognition, DSSCs in red at VLT of 7\% and 10\% showed lower performance values by $61.51 \%$ and $72.2 \%$, respectively, than the transparent glass in the case of $\mathrm{C} 1$. In the case of sample C2, red DSSCs at VLT 7\% recorded a performance value of $25.25 \%$ while blue DSSCs at VLT of $18 \%$ showed a performance value of $89.90 \%$. In the case of C 3 , red DSSCs at VLT of $7 \%$ recorded the lowest performance value of $3.45 \%$. The highest performance value of $75.86 \%$ was found for glasses with green and blue films as shown in Table 9. 
Table 9. Shape recognition graphs for all DSSC types according to color and VLT.

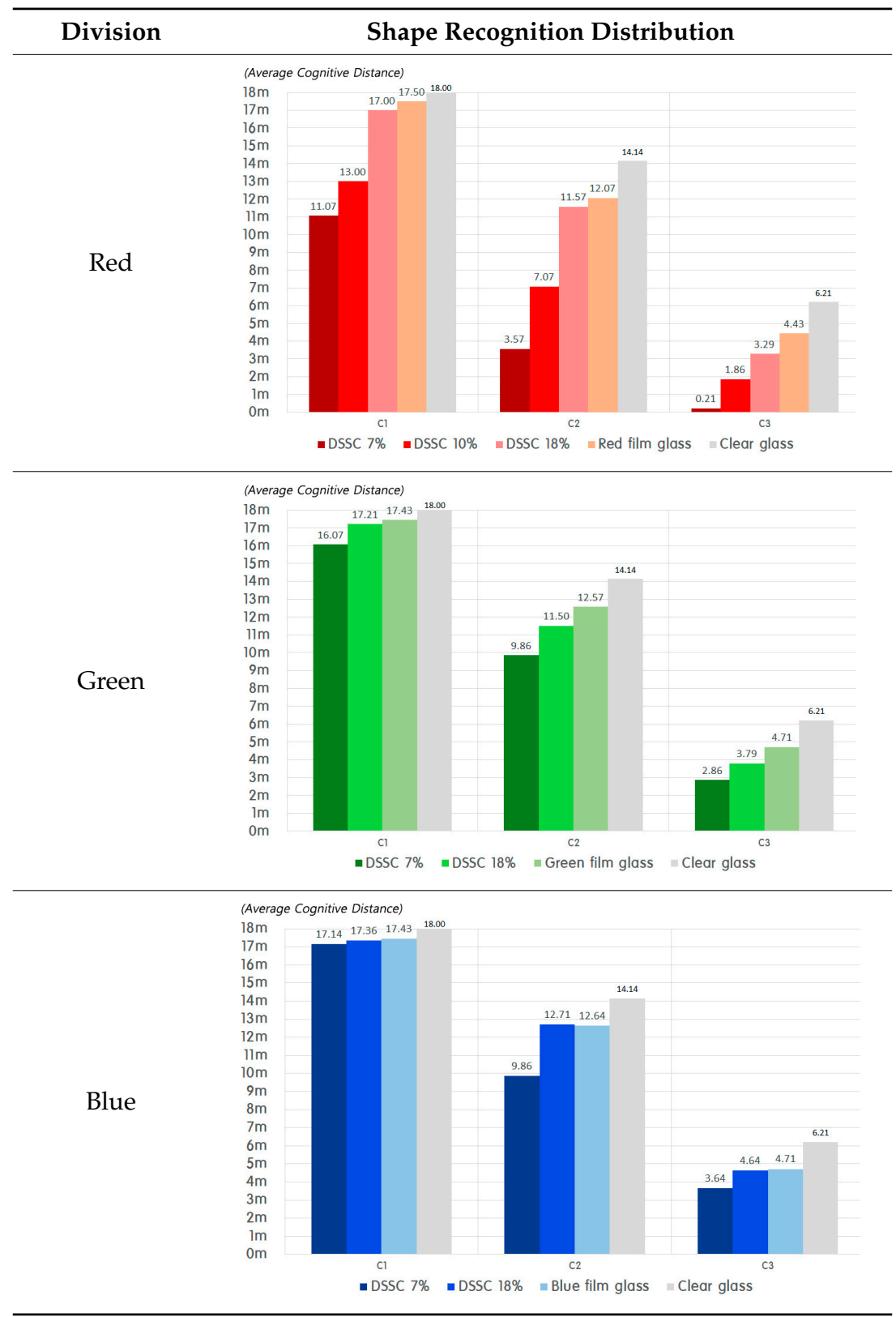

As a result of the evaluation, openings with attached films showed better performance in shape recognition that was not significantly affected by color or section. They were superior to DSSCs. However, blue DSSCs at VLT of $18 \%$ showed similar or better performance than windows with films. Among DSSCs, blue series had the best shape recognition while red ones showed the lowest performance. However, red series showed a tendency to improve the shape recognition performance by increasing VLT values. Red DSSC at VLT of $18 \%$ showed similar performance to green ones at VLT of $18 \%$.

\section{Conclusions}

As a result, when evaluating color expression, it was possible to confirm the range of color expression visually based on three points: red, blue, and green. In particular, although window colors are recognized as similar ones visually, the actual sense in color accepted and expressed through openings could show differences. The area could also be identified in the coordinate system. In 
addition, it was confirmed that the region had a unique range depending on the material or a distinctive direction in which it increased according to VLT value. In aspects of shape recognition, DSSCs were found to have lower ability in shape recognition than windows with color films except for those with blue films at VLT of $18 \%$. This might be due to differences of the dye, electrolyte, and color used in producing DSSCs.

Results of this study suggest that it is possible to measure colored indoor environment and shape of openings/windows with DSSCs. In particular, in case of colored indoor environment, its expression on windows could be measured quantitatively using gamut overage as a display concept. In addition, the visibility factor could provide proper data on colors to be expressed at higher levels. SPD and CAF methods used in previous studies were accurate enough for simulation. However, they were expensive and difficult to select from data. Thus, the proposed method turned out to be an optimized assessment tool at low cost that could produce numerical expression. It could be used in various ways by visually expressing the range of colors. The measurement of color expression through the gamut overage is considered to be significant in that it contains inherent physical properties of the dye and film layers used in windows and DSSCs overall.

The shape recognition was quantified by Landolt ring measurement used in visual treatment. However, the lack of complete quantification based on subjective investigation from evaluators was considered a limitation. However, it could be expressed by measuring the shape or the visible distance of various openings in comparison with the transparent glass as a ratio value. It is also meaningful in terms of deriving a numerical value that can be used as a criterion for selecting the opening. In the current study, films used to express the color of the window on the market showed no significant deviation from respective colors. Performance values of $96 \%, 85 \%$, and $71 \%$ were recorded for $\mathrm{C} 1, \mathrm{C} 2$, and C 3 types, respectively. However, most DSSCs turned to be inferior in shape recognition due to the use of dyes and electrolytes. On the other hand, blue DSSCs at VLT of $18 \%$ showed similar values to those used in the market. They were expected to be improved through continuous investigation.

In summary, this study examined the evaluation method for the quantification of indoor environment along with the evaluation of performances of DSSCs and a series of windows. As a result, it could be pointed out that the overall performance of DSSCs should be improved in aspects of color expression and shape recognition in order to show enough environmental controllability in comparison with existing windows having dye-sensitized solar cells. Furthermore, green DSSCs at VLT 18\% showed better color expression than existing film windows, although they had similar shape recognition by comparison. This is the most significant point according to found clues toward performance improvement.

It would be worth to discuss further about the appropriateness of the proposed method. It is also necessary to set up a standard monitor for measuring color expression and reform target modules for assessing shape recognition. In aspects of color expression, visual data could be provided by various experiments. Further research is also needed for the numerical interpretation stage. In addition, follow-up studies need to be conducted on structures of blue and green DSSCs at VLT of $18 \%$ that could have higher performances to improve the indoor environment by these solar cells.

Author Contributions: Conceptualization, J.-H.K.; Methodology, J.-H.K. and S.-H.H.; Software \& Validation, J.-H.K. and S.-H.H.; Data Analyses, J.-H.K. and S.-H.H.; Data Curation, S.-H.H.; Writing-Original Draft Preparation, J.-H.K.; Writing-Review \& Editing, J.-H.K. and S.-H.H.; Supervision, S.-H.H.; Project Administration, S.-H.H.; Funding Acquisition, S.-H.H.

Funding: Grant funded by the Ministry of Science and ICT of Korea for First-Mover Program for Accelerating Disruptive Technology Development (NRF-2018M3C1B9088457).

Acknowledgments: This research was supported by the National Research Foundation of Korea (NRF).

Conflicts of Interest: The authors declare no conflict of interest. 


\section{References}

1. Hwang, H.; Lee, H. Parametric Model for Window Design Based on Prospect-Refuge Measurement in Residential Environment. Sustainability 2018, 10, 3888. [CrossRef]

2. Jeong, I.; Kim, J. Comparative Performance Evaluation of Advanced Daylighting Glazing Systems by Scale Model Measurements. J. Korea Inst. Ecol. Archit. Environ. 2004, 4, 27-35.

3. Kim, J.; Shim, I. Visual Performance Evaluation of Daylighting System with Sloped Lightshelves. J. Korea Inst. Ecol. Archit. Environ. 2006, 6, 3-10.

4. Oh, S. A Comparative Study on Daylighting Performance Prediction of Light Tube and Dish Concentrator. J. Energy Eng. 2012, 21, 124-132. [CrossRef]

5. Chung, Y.; Kim, C.; Kim, J. A Study on the Evaluation of Interior Atmosphere in Atrium with Glass Colour. Korean J. Ecol. 2003, 3, 51-58.

6. Kim, I. Accuracy Evaluation of a Calculation Tool Based on the Spectral Colour Property of Indoor Luminous Environments. Build. Environ. 2018, 139, 157-169. [CrossRef]

7. Kim, I. Development of a Colour Quality Assessment Tool for Indoor Luminous Environments Affecting the Circadian Rhythm of Occupants. Build. Environ. 2017, 126, 252-265. [CrossRef]

8. Kim, J. A Study on Perovskite Solar Cell Characteristics of Photoelectrode Fabrication. Master's Thesis, Gachon University, Gyeonggi-do, Korea, 2017.

9. Chonnam National University. Construction of Semi-Permeable Photovoltaic Cell Building Shell Module Capable of Various Colors for the Esthetics of Urban Architecture; Final Report; Ministry of Land, Infrastructure, and Transport: Sejong, Korea, 2019.

10. Chungang University. The Development of a Monitor Evaluation Method for Graphic Experts; Final Report; National Research Foundation of Korea: Daejeon, Korea, 2013.

11. Zhang, L.; Lin, H.; Cheng, Y.; Xu, J.; Xiang, X.; Wang, C.; Lin, S.; Wang, Y. Color-Filtered Phosphor-in-Glass for LED-lit LCD with Wide Color Gamut. Ceram. Int. 2019, 45, 14432-14438. [CrossRef]

12. Zhang, L.; Lin, H.; Xiang, X.; Cheng, Y.; Hua, C.; Wang, C.; Lin, S.; Xu, J.; Wang, Y. Nanostructured NdF 3 Glass Ceramic: An Efficient Bandpass Color Filter for Wide-Color-Gamut White LED. J. Eur. Ceram. Soc. 2019, 39, 2155-2160. [CrossRef]

13. Namgoong, J.-W.; Kim, S.-H.; Chung, S.-W.; Kim, Y.-H.; Kwak, M.-S.; Kim, J.-P. Aryloxy-and Chloro-Substituted Zinc(II) Phthalocyanine Dyes: Synthesis, Characterization, and Application for Reducing the Thickness of Color Filters. Dye. Pigment. 2018, 154, 128-136. [CrossRef]

14. Xiang, X.; Lin, H.; Xu, J.; Cheng, Y.; Wang, C.; Zhang, L.; Wang, Y. CsPb(Br,I $)_{3}$ Embedded Glass: Fabrication, Tunable Luminescence, Improved Stability and Wide-Color Gamut LCD Application. Chem. Eng. J. 2019, 378, 122255. [CrossRef]

15. Kim, M. Optically Adjustable Display Color Gamut in Time-Sequential Displays Using LED/Laser Light Sources. Displays 2006, 27, 137-144. [CrossRef]

16. Huang, W.; Li, J.-M.; Yang, L.-M.; Jin, Z.-L.; Zhong, Z.-G.; Liu, Y.; Chou, Q.-Y.; Li, F. Local Dimming Algorithm and Color Gamut Calibration for RGB LED Backlight LCD Display. Opt. Laser Technol. 2011, 43, $214-217$. [CrossRef]

17. Hung, K.; Pei, C.-C.; Hu, C.-J.; Yang, T.-C. Manipulation Image Processing Algorithmic Technology to Realize 1.8" RGBW Transflective TFT-LCDs with Adjustable Colour Gamut. Displays 2008, 29, 526-535. [CrossRef]

18. David, L.; Lloyd, C.J.C. Colour Display Gamuts and Ambient Illumination. Displays 1994, 15, $39-43$.

19. Kubota, S. Effects of Ambient Lighting Conditions on Luminance Contrast and Color Gamut of Displays with Different Technologies. Adv. Hum. Factors Ergon. 1995, 20, 643-648.

20. Yanfang, X.; Zhen, W.; Min, H.; Haoxue, L. Investigation of the Impact of Surrounding Light on Monitor' Color Showing. Procedia Environ. Sci. 2011, 10, 499-504. [CrossRef]

21. Park, Y.; Choi, G. Interaction between Space and an Objet through Spatial Experience. Korean Soc. Basic Des. Art 2008, 9, 399-411.

22. Lee, M. A Study on the Order of the Spatial Shape based on Neuroaesthetics. Master's Thesis, Hongik University, Seoul, Korea, 2017.

23. Kim, Y. Cognitive Space Planning in Consideration of Cognitive Efficiency of Visual and Perceptual Information: Focused on Visual Information of Moving Object. Master's Thesis, Kyonggi University, Seoul, Korea, 2003. 
24. Ha, N.; Choi, J.; Kim, H. The Effects of the Relative Legibility of Optotypes on Corrected Visual Acuity. J. Korean Ophthalmic Opt. Soc. 2015, 20, 177-186. [CrossRef]

25. McAnany, J.J.; Alexander, K.R. Spatial Frequencies Used in Landolt C Orientation Judgments: Relation to Inferred Magnocellular and Parvocellular Pathways. Vis. Res. 2008, 48, 2615-2624. [CrossRef]

26. Lai, Y.; Wang, H.; Hsu, H. Development of Visual Acuity in Preschool Children as Measured with Landolt C and Tumbling E Chart. J. Am. Assoc. Pediatr. Ophthalmol. Strabismus 2011, 15, 251-255. [CrossRef] [PubMed]

27. Wu, F.; Chou, Y.; Tseng, C. Influence of Primary Screen Color Landolt-C Rings on Vision Consistency Differentiation Ability. Procedia Manuf. 2015, 3, 4520-4527. [CrossRef]

(C) 2019 by the authors. Licensee MDPI, Basel, Switzerland. This article is an open access article distributed under the terms and conditions of the Creative Commons Attribution (CC BY) license (http://creativecommons.org/licenses/by/4.0/). 